\title{
Pivoting in a Pandemic: Supporting STEM Teachers' Learning through Online Professional Learning during the Museum Closure
}

\author{
Jamie Wallace, Anna MacPherson, Karen Hammerness, Michael Chavez-Reilly, and Preeti Gupta \\ American Museum of Natural History, New York, NY \\ Keywords: Pandemic, COVID-19, museum, evaluation, online learning, STEM programs, teacher education, teacher professional learning, virtual field trips \\ Publication Date: August 30, 2021 \\ DOI: https://doi.org/10.15695/jstem/v4i3.11
}

\begin{abstract}
Drawing on data from STEM teacher education programs collected during museum closure due to the COVID-19 pandemic, this article examines the shifts that a large natural history museum made in educational programming. We explore three questions; who participated; the nature of participants' experiences with programming; and what we learned as an education department within and across teacher education programs by drawing on systematically collected quantitative and qualitative data (attendance, surveys, focus groups, and interviews). We draw upon case study data to delve into our online teacher professional learning offerings as an example, and then ground it within data and findings from our other teacher education programs at the museum offered during closure. We conclude by identifying implications for developing ongoing work with teachers going forward. Three central implications were: 1) continue to offer remote teacher professional learning sessions, 2) develop a shared vision of good science teaching online, and 3) model pedagogy that supports this shared vision. During a time of extreme uncertainty and tragedy, this article seeks to document and capture the innovative approaches developed to help support teachers, continue educational efforts, strive to act as an agent of change, as well as address challenges that emerged in the move to remote programming.
\end{abstract}

\section{INTRODUCTION}

On March 13th, 2020 the American Museum of Natural History (AMNH) closed its doors to the public for the first time in history due to the COVID-19 global pandemic public health emergency, alongside other New York City museums and cultural institutions (Pogrebin and Cooper, 2020). The New York City Department of Education closed school buildings on March 16th and moved all in-person public school learning online on March 23th, 2020 (Shapiro, 2020). Museum educators were faced with the unique challenge of reimagining learning experiences, resources and materials for teachers, students, children and families, and the public. There was no way to anticipate the length of time of the crisis, its potential impact, nor the best ways to reach the community. Museum staff were also adjusting to quarantining, and remote school and work. The financial impact of the pandemic upon the museum, and in turn, on staff posed further challenges. The longer the museum remained closed, the more revenue was lost. To address the loss of revenue, a set of measures were established including reducing staff time; and ultimately, furloughing and letting go of employees (Jacobs, 2020). Yet under these tenuous circumstances, within a few weeks a context of invention and creativity emerged with museum educators, designers, and researchers pivoting quickly to design multiple new online versions of programs, redesign in-person events for online platforms, and develop instruments to document the experience. While the Museum closure from March 13th to September 9th was a period of strain, uncertainty, and tragedy, it also prompted remarkable innovation, collaboration, and creativity.

Pivoting in a Pandemic Evaluation. Drawing on data from STEM teacher education programs collected during the museum closure due to the COVID-19 pandemic, this article examines the shifts that the museum made in educational programming. We build upon research on education in emergencies which emphasizes the importance of research and evaluation during crises to support strategic thinking and further work. The scholarship in this area is driven by the 
need to ensure access to free, safe, public education to people affected by emergencies. It includes attention to the prevention of emergencies but also to supports for recovery as well as learning from a crisis to help prepare better and prevent new crises - or what one researcher called "amelioration, reparation and preparation" (Hallgarten, 2020). During crises, mitigating programs are often quickly put in place without gathering impact evidence. This prevents learning of long-term lessons that can help with preparedness and mitigation in the future. Scholars argue for the development of a richer base of evidence for efforts so that we can learn from them. Researchers in the education in emergencies literature underscore the critical role of research and evaluation during crises; to continue to learn about what is relevant, transferrable and adaptable for long-term crises and disease-related emergencies. Our evaluation was also informed by several large-scale evaluations conducted across museums and cultural institutions to document the impact of the pandemic (AAM and Dynamic Benchmarking, 2020; UNESCO, 2020). Across studies, it is evident that many museums adapted to online environments; this was a considerable shift given survey findings from February 2020 (prior to the pandemic outbreak in the United States) revealing that less than $50 \%$ of art museum directors considered providing digital experiences for audiences unable to visit the museum in person as a priority (Sweeney and Frederick, 2020).

Building on the literature on education in emergencies which has underscored the importance of conducting research and evaluation even in a crisis, AMNH's Research and Evaluation Group conducted an evaluation of the museum's teacher education programs. The purpose of the evaluation was multi-faceted: to document this critical moment in the museum's history; to capture some of the decisions made during this time; to reveal the learning that occurred; and to support ongoing learning - especially as we may continue to require new settings for learning and may be living in a new learning and museum environment even after the crisis has passed. Through analysis of a case study on K-12 teacher professional learning offerings and a synthesis across teacher education programs, we explore three questions pertinent to all of our teacher programs and grounded in equity and access: 1) Who participated? Are there any notable trends in terms of access and participation?; 2) How do teachers respond to the programming during this time? What are participants' experiences and what feedback do they provide?; and 3) What shifts did we make to our work, and why? What did we learn as an education department within and across our STEM teacher education programs?

Exploring Virtual Teacher Professional Learning. In this paper, we focus upon the findings from STEM-focused teacher education programming at the museum, using data and findings from the Gottesman Center for Science Teach- ing and Learning (subsequently referred to as Gottesman) professional learning (PL) offerings for K-12 teachers as a case study. We use data from Gottesman as an individual case to explore the adaptation to online programming during the early months of the pandemic and the challenges encountered. We then situate the findings in relation to those synthesized across teacher programming; this includes our professional learning opportunities for teachers (through Urban Advantage, a partnership program with NYC Department of Education and seven other cultural institutions); our online teacher education courses (Seminars on Science and Massive Open Online Courses on Coursera, asynchronous science courses taught by museum scientists and educators); and our 15-month full time Master of Arts in Teaching Earth Science Residency Program which prepares middle and high school Earth Science teachers.

\section{METHODS}

Using a systematic, mixed methods approach, this evaluation was a collaborative effort that integrated perspectives and voices from multiple stakeholders and drew on data collected specifically during the time the museum was closed to the public (March 13th-September 9th, 2020). To study the shifts in Gottesman's PL sessions, we used attendance records and demographic data from applications and surveys to summarize shifts in participation. We administered surveys following teacher PL offerings that asked about participants' experiences during the online sessions. We worked together with Gottesman educators to modify pre-existing surveys from previous workshops. We analyzed survey data from the previous year to provide a comparison. To learn more about where participants were located and to probe questions about equitable participation by borough and district, we incorporated geo-spatial data analysis with zip codes provided on surveys, using QGIS software drawing from publicly-available US Census data. We gathered data from two focus groups with participants, as well as informal discussions with staff members to gather qualitative data about the shifts that the program underwent. Finally, we engaged in member checks across departments to ensure validity.

\section{Professional Learning in Gottesman and the Shift to On-} line Learning. The mission of the Gottesman Center is to improve science teaching and learning by providing intensive professional learning that supports teachers in learning scientific content and research-supported pedagogical practices. Informed by research on teacher learning, Gottesman offerings contain design features considered most effective for science teacher professional development with active participation and immersion in inquiry experiences, provide models of effective inquiry-based instruction, are content 
focused, closely connected to practice with time dedicated to reflect on classroom practice and experiences, support collaboration with other teachers, and use curriculum materials that are educative for teachers and students aligned with the Next Generation Science Standards (NGSS) and NYS Science Learning Standards (NASEM, 2016; Darling-Hammond et al., 2017; Wilson, 2013). Gottesman PL focuses upon investigation of scientific phenomena (for example, extreme weather events, Darwin's finches, and plate tectonics). In particular, Gottesman aims to support teachers in using Museum resources and curriculum in the classroom and leading field trips within the Museum's galleries and exhibitions. Annually about 4,000 teachers participate in these learning opportunities. In addition to workshops and institutes, Gottesman hosts Educators' Evenings on special exhibitions as well as NYC PL days twice yearly. At the beginning of the Museum closure in mid-March, PL offerings for teachers were suspended and school group visits were discontinued. In late May, following an announcement from the NYC DOE Chancellor Carranza that teacher PL would proceed remotely, Gottesman modified plans for PL offerings for online delivery.

The first online PL offerings were piloted during Chancellor's Day on June 4th, an annual day dedicated to teacher learning across the city. Sessions were reduced in number and scope. The Center offered five sessions (typically there would be seven) to fewer participants (reducing capacity from 50 to 25 maximum per session) on different topics targeted for diverse grade bands simultaneously using the Zoom platform. Several sessions were adapted from previous offerings, such as investigating weather phenomena using an online graphing tool and incorporating real weather data and modeling the ecology of Lyme Disease. New
Table 1. Participation data from Chancellor's Day PL on June 4, 2020.

\begin{tabular}{|c|c|c|c|c|}
\hline Topic & $\begin{array}{c}\text { Grade } \\
\text { Band } \\
\text { Designated }\end{array}$ & Applicants & $\begin{array}{l}\text { Attended / } \\
\text { Enrolled }\end{array}$ & $\begin{array}{c}\text { Attendance } \\
\text { Rate }\end{array}$ \\
\hline $\begin{array}{l}\text { "Teaching metacognition as } \\
\text { an explicit skill }\end{array}$ & $3-5$ & 24 & $17 / 24$ & $71 \%$ \\
\hline $\begin{array}{l}\text { "Using the Museum to } \\
\text { support social emotional } \\
\text { learning }\end{array}$ & K-12 & 64 & $23 / 25$ & $92 \%$ \\
\hline $\begin{array}{l}\text { "Analyze and interpret data } \\
\text { to investigate how blue } \\
\text { whales, the largest animal } \\
\text { to ever live, survive }\end{array}$ & $6-12$ & 29 & $25 / 29$ & $86 \%$ \\
\hline $\begin{array}{l}\text { Modeling the ecology of } \\
\text { Lyme disease }\end{array}$ & $6-12$ & 28 & $17 / 28$ & $61 \%$ \\
\hline $\begin{array}{l}\text { Investigate weather } \\
\text { phenomena using real } \\
\text { weather data from the } \\
\text { graphing tool "Patterns: } \\
\text { investigating Weather and } \\
\text { Climate" }\end{array}$ & $6-12$ & 30 & $17 / 30$ & $57 \%$ \\
\hline Total & & 175 & $99 / 136$ & $73 \%$ \\
\hline
\end{tabular}

sessions were developed and featured for the first time; for example, "Using the Museum to Support Social Emotional Learning," "Teaching Metacognition as an Explicit Skill," and a teacher case study investigating blue whale feeding behavior. Similar to previous in-person PL, teachers were eligible to receive Continuing Teacher and Leader Education credit, a NYS requirement for teachers. Also similar to previous years, registration was sold out and limits were placed on the number of participants. Unlike previous years, there was no cost to attend.

Informed by the piloting in June, Gottesman then offered eleven PL sessions remotely throughout August. Similar to June, sessions took place on Zoom and were free of charge.

Table 2. Participation data from teacher PL throughout August 2020.

\begin{tabular}{|c|c|c|c|c|c|c|}
\hline Topic & Date & $\begin{array}{l}\text { Grade Band } \\
\text { Designated }\end{array}$ & Format & Applicants & $\begin{array}{l}\text { Attended / } \\
\text { Enrolled }\end{array}$ & Attendance Rate \\
\hline${ }^{*}$ Facilitating student talk at home & $8 / 5 / 2020$ & $3-8$ & 3-hr session & 113 & $28 / 36$ & $78 \%$ \\
\hline $\begin{array}{l}\text { Analyze and interpret data to investigate how blue whales, the larg- } \\
\text { est animal to ever live, survive }\end{array}$ & $\begin{array}{c}8 / 5 / 2020 \\
\text { and } \\
8 / 6 / 2020\end{array}$ & $6-12$ & $\begin{array}{l}2 \text { day, } 3-h r \\
\text { session }\end{array}$ & 42 & $23 / 36$ & $64 \%$ \\
\hline $\begin{array}{l}\text { Investigate weather phenomena using real weather data from the } \\
\text { graphing tool 'Patterns: investigating Weather and Climate' }\end{array}$ & $8 / 11 / 2020$ & $6-12$ & 3-hr session & 53 & $31 / 35$ & $89 \%$ \\
\hline "Nature journaling for culturally expansive learning & $8 / 14 / 2020$ & $6-8$ & 3-hr session & 48 & $24 / 35$ & $69 \%$ \\
\hline Science practices in Darwin's garden & $8 / 17 / 2020$ & $6-8$ & 3-hr session & 33 & $24 / 26$ & $92 \%$ \\
\hline Teaching metacognition as an explicit skill & $8 / 18 / 2020$ & $3-5$ & 4-hr session & 47 & $19 / 31$ & $61 \%$ \\
\hline Using the Museum to support social emotional learning & $8 / 19 / 2020$ & $\mathrm{~K}-12$ & 3-hr session & 76 & $22 / 34$ & $65 \%$ \\
\hline${ }^{*}$ Emphasizing engagement & $8 / 19 / 2020$ & $6-8$ & 3-hr session & 36 & $18 / 25$ & $72 \%$ \\
\hline Modeling the ecology of Lyme disease & $\begin{array}{l}8 / 19 \text { and } \\
8 / 20 / 2020\end{array}$ & $6-12$ & $\begin{array}{l}\text { 2-day, 3-hr } \\
\text { session }\end{array}$ & 40 & $21 / 35$ & $60 \%$ \\
\hline $\begin{array}{l}\text { "Facilitating a Virtual Field Trip to the Hall of North American } \\
\text { Mammals }\end{array}$ & $8 / 20 / 2020$ & $3-5$ & 2-hr session & & $10 / 15$ & $67 \%$ \\
\hline${ }^{*}$ Facilitating a Virtual Field Trip to the Hall of Planet Earth & $8 / 20 / 2020$ & $6-8$ & 2-hr session & & $11 / 16$ & $69 \%$ \\
\hline Total & & & & 488 & $231 / 324$ & $71 \%$ \\
\hline
\end{tabular}

Note: "Asterisk indicates a new session that had not been offered previously. 
Offerings focused on diverse topics targeted to various grade levels, such as facilitating student talk at home, science practices in Darwin's garden, and nature journaling for culturally expansive learning.

In addition, in August 2020, Gottesman educators designed and conducted two pilot PL sessions about Virtual Field Trips. A Virtual Field Trip experience consists of a virtual visit to a Museum exhibition hall via Google Arts and Culture, accompanied by a set of texts, guiding questions, and writing prompts and scaffolds that lead students through an investigation in the hall. (AMNH Virtual Field Trips can be found online at www.amnh.org/plan-your-visit/ field-trips/virtual.) Each field trip has a "core" activity and extension activities. The PL sessions aimed to introduce teachers in grades 3-8 to the Virtual Field Trip resources available on the Museum's website, allow them to experience a Virtual Field Trip as a learner, and collect feedback about the strengths and weaknesses of the Museum's existing resources. One session was focused on conducting a Virtual Field Trip to the Hall of North American Mammals and was aimed at teachers in grades 3-5. During this experience, students explore habitat dioramas to learn how animals must be adapted to an environment to survive. The other session was focused on conducting a Virtual Field Trip to the Hall of Planet Earth and was aimed at teachers in grades 6-8. During this experience, students investigate how plate tectonics explain specific Earth formations, such as ocean basins, continents, and mountains. Throughout March 13th-September 9th, Gottesman offered a total of 16 online PL sessions with 330 teachers.

\section{FINDINGS FROM THE SHIFT TO ONLINE PROFESSIONAL LEARNING}

No Evidence of Inequitable Participation in Terms of Geography and Demographics. According to application data, nearly $70 \%$ of participants worked in Title I schools indicating high numbers of students from low-income households. Attendance rates were similar across both sets of online PL offered during the closure (73\% Chancellor's Day, $71 \%$ August sessions). A total of 99 teachers participated in 5 sessions for Chancellor's Day 2020 during the Museum closure, which was online, free, and reduced in scale; comparatively, 211 teachers participated across 8 sessions for Chancellor's Day 2019 before the pandemic, which was an in person, paid event. Survey data indicate that participants were mostly experienced, veteran teachers with more than 10 years of experience (61\% Chancellor's Day, 62\% August sessions), with a small percentage of teachers with less than two years of experience (5\% Chancellor's Day, 2\% August sessions). In addition, roughly three quarters of the teachers were very familiar with AMNH educator resources, through participating in previous PL (see Figure 1) and/or
Table 3. Comparison of teacher characteristics using survey data from Chancellor's Day PL before and during the Pandemic.

\begin{tabular}{lcc}
\hline \multirow{2}{*}{ Teacher Participant Characteristics } & \multicolumn{2}{c}{ Chancellor's Day } \\
\cline { 2 - 3 } & $\begin{array}{c}\text { Pre-COVID, } \\
\text { 2019 In person } \\
\text { (N=166) }\end{array}$ & $\begin{array}{c}\text { During COVID, } \\
\mathbf{2 0 2 0} \text { Online } \\
\text { (N=80) }\end{array}$ \\
\hline Grade(s) taught & & \\
\hline Elementary & $14 \%$ & $20 \%$ \\
K-2 & $16 \%$ & $20 \%$ \\
$3-5$ & $16 \%$ & $26 \%$ \\
Middle School (6-8) & $53 \%$ & $33 \%$ \\
High School (9-12) & $1 \%$ & $1 \%$ \\
Other & & \\
\hline Subject(s) taught & $30 \%$ & $24 \%$ \\
\hline Living Environment & $17 \%$ & $12 \%$ \\
Physical Science & $6 \%$ & $8 \%$ \\
Integrated Science & $23 \%$ & $22 \%$ \\
Earth Science & $24 \%$ & $35 \%$ \\
Other & & \\
\hline
\end{tabular}

using AMNH resources to support their curriculum (82\% Chancellor's Day, 78\% August sessions). Although at a reduced scale, survey data on participant characteristics from Chancellor's Day online in 2020 during the pandemic $(n=80)$ was comparable to the previous year in person $(n=166)$, with few noticeable differences in terms of grades and subjects taught (see Table 3). Thus, we can determine that the profile of teacher participants did not change substantively.

Geospatial analysis of zip code data collected in August surveys showed that participating teachers' schools were heavily concentrated in the New York City area and were fairly evenly spread across boroughs. These data were drawn from $92 \%$ of survey participants who provided usable school zip codes within the United States $(n=147)$. Looking specifically at GIS maps and census data layered onto NYC school districts, a slightly higher number of survey participants in the August PLs were from schools in the Bronx, particularly from Districts 9 and 11. Overall, participation did not change dramatically when sessions transitioned online and there was

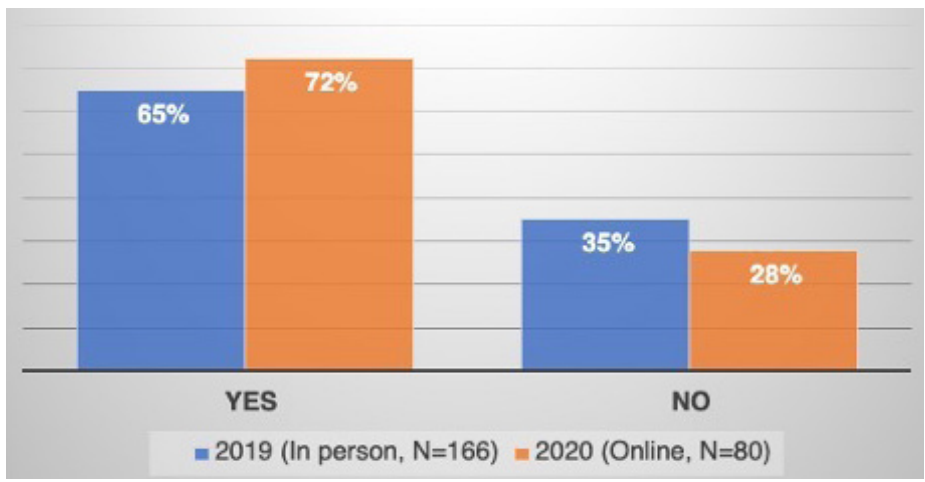

Figure 1. Comparison of participation in previous AMNH teacher professional learning from Chancellor's Day survey data in 2019 and 2020. 


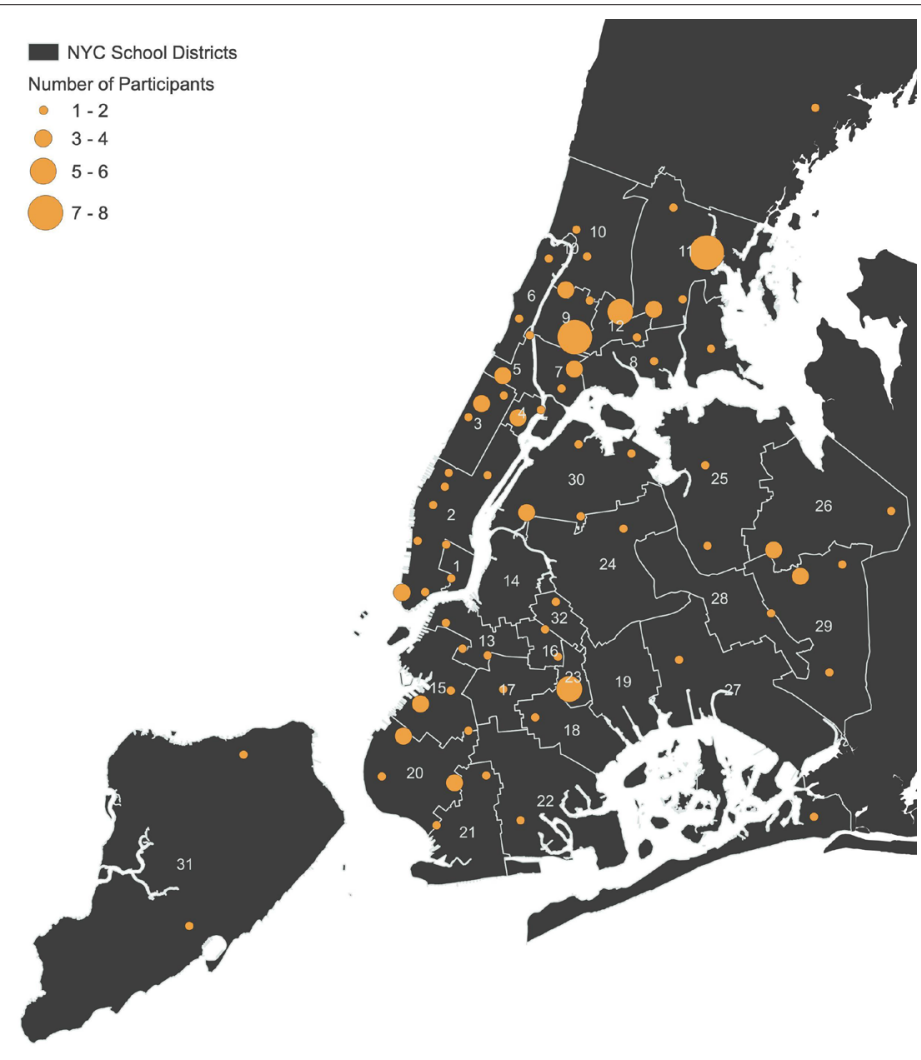

\section{School Districts of Gottesman Professional Learning Survey Participants}

Figure 2. School locations of survey participants from August professional learning by NYC school district. Sources: US Census, NYC OpenData, GIS.ny.gov, AMNH. Projection: NAD 1983 HARN StatePlane New York East FIPS 3101.

no evidence for inequitable participation across districts.

A Smooth Transition to Remote Learning. Overall, teachers' feedback about online PL sessions was positive; many described how sessions were informative, interactive, and applicable to their immediate teaching needs. For example, a teacher from Chancellor's Day commented, "I am excited about the new and relevant resources that I can use in the classroom! As for the Zoom meetings - I feel like it worked extremely well. There was a high level of engagement in all the groups that I was in. It helps to have everything digitized. I would be interested in other PD opportunities like this." Another shared, "I want this PD to be brought to schools for whole staff to reflect on to better support our students!" Noting a smooth transition from onsite to online, a teacher from an August session commented, "I was so surprised at the quality of this workshop especially being interactive which I was clearly not expecting. I loved the breakout session. [It] reminded me of the past inhouse PDs and that was awesome." Others referenced opportunities to use what they learned immediately. Teachers' strongly positive response to solely online learning surprised us. We had hoped that they would find the experience helpful and supportive, but had expected they might really miss the in-person learning experience. We were encouraged by the degree of their enthusiasm about the move to remote learning.

Online PL Provided a Helpful Model of Remote Teaching. Consistent with research findings about the features of strong professional learning, teachers in Gottesman reported that sessions helped them learn about ways to teach remotely by providing models of online instruction in science (Haug and Mork, 2021; Penuel et al., 2007). Teachers described wanting to reproduce aspects of the experience in their own teaching. For instance, a Chancellor's Day participant shared, "I can use the modeling process - both technology (break into groups, collaboration on jamboard, back to the whole group) and content ... in my classroom to engage students and encourage collaboration and discussions." Another teacher drew on the variety of resources provided and formats that could be used for lessons, noting, "Really like the variety of resources in the lesson, and the variety of lesson formats. I will try to reproduce this with my students - everything was great, both in terms of data set, buy-in (suspense!), and pedagogy." Similarly participants from August sessions planning for online learning in the fall commented, "I will be online in the Fall so having this as an online workshop helped to model aspects I can recreate in my lessons" and "I felt like since we were actually using the tools, it helped me to better visualize how I would use it with my students in a remote setting." Another shared, "I thought this was a great session and love the use of real data for students. I also liked seeing how to develop a model - I can use this idea with lots of different concepts (in Earth science and in chemistry) and I had never seen it done before so it was very helpful!"

According to survey data, nearly $80 \%$ of teachers described ways they planned to integrate what they learned in PL (e.g., strategies, resources, tools) into their instruction. Many teachers who participated in sessions focused on using graphing tools and secondary data sets to investigate anchoring phenomena shared their intent to use the graphing tools with students to introduce the NGSS Science and Engineering Practice of analyzing and interpreting data. For instance, a teacher commented, "I will be using this in my atmospheric science unit to help intro[duce] data analysis and graphing interpretation...These tools are useful...so I can allow [my students] to experiment and discover new ways to represent the data to answer essential questions." Another teacher noted, "I can use this phenomenon...Data analysis is a skill that my students consistently need to practice. I would incorporate strategies like 'See, Think, Wonder' and 'I squared' when analyzing data figures... [and would] conclude by having students construct a scientific explanation using the Claim, Evidence, Reasoning strategy."

Teachers identified local scientific phenomena as an important resource during remote learning. From a session on 
nature journaling for culturally expansive learning, a teacher shared, "I can definitely use this in my science classrooms as they make observations. Even during remote learning, like we did, [students] can make observations from their window or their front porch. The act of drawing and including details can be very peaceful and grounding which is beneficial during times like this." Similarly, in a session on Science Practices in Darwin's Garden, a teacher commented, "I look forward to taking my s[tudent]s out on an exploration tour around our school's block. [The facilitator's] tour of his neighborhood was engaging and eye-opening!"

Teachers also highlighted challenges of the pandemic when thinking about how to use resources and materials from PLs when teaching online. For instance, from a session on social-emotional learning (SEL), "to help the students to deal with their emotions. Especially in this time they might get frustrated to be taking remote learning at home which is something totally new to them." Others in the session shared, "I can use the Model of Emotion for myself but also...to teach my students about emotions, how they progress, and how to deal with them," "The routine of sketching can be incorporated in my classroom to share perspectives and interpretations," and "Great ideas on how to use exhibits to enhance understandings of feelings." Some teachers also planned to turn key content and resources to school colleagues.

Online Experience Comparable to In-person. The majority of teachers across the PLs reported that the online experience recreated some of the most important aspects of in-person sessions such as engagement in content, quality of discussion, and immediate usefulness of strategies to teaching, revealing that key features that matter for science teachers' learning were still in place, even in online instruction. In addition, many participants expressed benefits to the online format such as accessibility, convenience, fewer distractions, and more opportunities to collaborate with people they might not have otherwise in randomized breakout groups. For instance, Chancellor's Day participants mentioned, "With the exception of providing my own coffee, today's session felt very much like the in-person [PL] experiences I've had at AMNH" and "The [PL] was just as informative and clearly presented as in-person quality." Providing greater depth and specificity, one teacher shared,

I was in the comfort of home with the headset on so it was engaging and easier to focus. Additionally, commuting can be stressful at times so without that worry and dread, it was much more engaging. Because of remote teaching these days, I found the technology used to engage and encourage collaboration in small groups was practical and applicable. Also, the topic ... is highly relevant to the pandem- ic... The discussion online seems to be the same as in-person because of the small group sessions built in throughout the PL.

Similarly, a teacher from an August session communicated, "I have attended an in person training and loved it! However, the online format did make it easier to make it to the workshop and I felt really engaged with the material as I did with the in person one. Since the materials of this workshop were all online, it made it easy to follow along." Another noted, "I feel I can attend now that I don't have to be there in person... it's hard to travel. I feel it's easier to discuss with others during breakout rooms without distraction from others. Doing these activities shows me how and why I can use them in the classroom." Numerous teachers echoed the sentiment that having small group discussions in breakout rooms within sessions provided a sense of connection, engagement, and collaboration with other teachers that resembled an in-person experience.

\section{Different Goals for Virtual Versus In-person Field Trips.}

To begin the Virtual Field Trip PL sessions, the facilitator began by asking participants why they chose to take their students to the Museum for in-person field trips and then what they were hoping their students would gain from a virtual trip. Similar ideas emerged during both discussions, which took place in the chat box of Zoom and then selected responses were highlighted by the facilitator. Participants identified "experience something new, unique, or exciting" as important for both in-person and virtual trips. However, while goals for in-person trips emphasized the "hands-on" nature of the experience and the importance of seeing artifacts in person, goals for virtual trips shifted toward "hear a new perspective," and several participants discussed wanting students to have access to experts or museum professionals (see Table 4). Teachers also did not spontaneously offer "connection to the curriculum" as an important goal of virtual trips, whereas they did for in-person and we have found this to be a central goal for field trips in previous evaluations. We were unable to probe the goals in further depth; however, we hypothesized that perhaps teachers were less focused on connecting to the curriculum because they were so focused on capturing students' attention and helping them have a positive experience, given the challenges of the rapid shift online during COVID-19.

\section{KEY THEMES ACROSS GOTTESMAN PROFESSIONAL LEARNING FINDINGS}

Strong Interest in Continued Online Teacher PL. A major learning from this time was that there is huge interest in online teacher PL. Survey data, 93\% from Chancellor's Day and $100 \%$ from August sessions, indicated teachers' strong 
Table 4. Virtual Field Trip PL participants' open-ended responses about why they go on field trips (in-person) and what they are hoping students gain from a virtual trip.

\begin{tabular}{|c|c|c|}
\hline \multicolumn{3}{|c|}{ Why do you go on in-person field trips? } \\
\hline Theme & Count & Illustrative quotation \\
\hline $\begin{array}{l}\text { Provide a hands-on } \\
\text { science experience with } \\
\text { artifacts in exhibitions }\end{array}$ & 13 & $\begin{array}{l}\text { "We go to expose them to materials and } \\
\text { resources we don't otherwise have access } \\
\text { to. For example, being able to touch a } \\
\text { meteorite, see moon rocks." }\end{array}$ \\
\hline $\begin{array}{l}\text { Experience something } \\
\text { new, unique, or exciting; } \\
\text { to spark interest }\end{array}$ & 5 & $\begin{array}{l}\text { "Students are engaged and excited about } \\
\text { the experience. It's an opportunity to leave } \\
\text { the school and the classroom" }\end{array}$ \\
\hline Enrich the curriculum & 3 & $\begin{array}{l}\text { "We go to tie in with science units, but we } \\
\text { make time to see a social studies related } \\
\text { exhibit while there, too" }\end{array}$ \\
\hline \multicolumn{3}{|c|}{ What are you hoping your students will gain from a virtual trip to the museum? } \\
\hline $\begin{array}{l}\text { Hear a new voice or } \\
\text { perspective; access to } \\
\text { scientific expertise }\end{array}$ & 9 & $\begin{array}{l}\text { "Give students access to a professional in } \\
\text { the field doing the real work" }\end{array}$ \\
\hline $\begin{array}{l}\text { Experience something } \\
\text { new, unique, or exciting; } \\
\text { to spark interest }\end{array}$ & 7 & $\begin{array}{l}\text { "Excite learners ... have students feel like } \\
\text { there are new, interesting, and real things } \\
\text { in the curriculum" }\end{array}$ \\
\hline $\begin{array}{l}\text { Access artifacts and } \\
\text { exhibitions virtually }\end{array}$ & 5 & $\begin{array}{l}\text { "I want to still to expose them to artifacts } \\
\text { and resources we can't get in the class- } \\
\text { room/online with our regular curriculum" }\end{array}$ \\
\hline
\end{tabular}

Note: Responses from both pilot sessions were analyzed together $(n=21)$. Participants typed their responses in the chat.

interest in participating in more remote PL offerings with AMNH. In the short term, learning from the June piloting and teachers' feedback informed Gottesman's decision to offer a series of sessions throughout August. In the longer term, Gottesman is drawing upon data from during the closure to plan continued remote offerings in the upcoming year. The Gottesman team made several shifts with remote offerings and continues to learn through their facilitation experiences and feedback from participating teachers, which informed their design of online workshops for the fall. As the move to teaching remotely was a rapid transition and required immense changes to instruction, there was a huge demand for online learning and professional support for teachers. It was critical for Gottesman to be able to meet teachers' needs during this time, particularly with providing support focused on specific science content and practices, an influential core feature of effective teacher learning as studies show correlations between how students learn specific content with increases in teachers' knowledge and skills (Desimone, 2009).

\section{Building Technology Support into Session Design is Critical for a Smooth Experience. Learning from experi-} ence facilitating sessions in June and the types of technology-related challenges that can surface, Gottesman established norms for remote delivery and created a document detailing the incorporation of technology support in advance of each session to help with any difficulties that arise. The team determined that a technology facilitator would be designated for each session, who could support various online aspects that can be challenging for one facilitator to manage while teaching, such as monitoring the chatbox, admitting participants into the session, arranging breakout groups, and tracking attendance. This would provide collaborative efforts for Gottesman educators to work together and support each other and provide an extra layer of support for teachers should the need for assistance arise. Additionally, the Center decided to integrate use of technology and how to implement it as a design feature of PL. Sessions featured new technologies and supported teachers in learning how to implement them in their remote teaching. For instance, sessions included how to use the chat, breakout rooms, and polling more effectively, in addition to Jamboard, Nearpod, Google Suite tools, Padlet, and strategies to engage learners and encouraging them to turn on cameras.

Broadening and Diversifying Professional Learning Offerings. For August sessions, Gottesman provided a variety of options and formats for teachers in response to the chaotic and challenging times of the pandemic and working remotely. August PL offerings included a variety of single and multiple day sessions with differing lengths. During this time, as well as planning for the fall, several new topics were introduced for sessions, such as social emotional learning, facilitating student talk at home, culturally expansive learning, and family engagement. These topics received great interest, and required wait lists as maximum capacity was reached early through applications. Thus, there was a shift to provide even more options and variety for teacher PL.

Planning for the fall, Gottesman educators collaboratively analyzed survey data together from summer sessions to inform planning for upcoming offerings. Engaging in conversations about how participation in sessions looked different during this time, the team brainstormed ways to emphasize transparency in terms of expectations for engagement in PLs ahead of time to encourage participation. In rethinking what active participation could look like online and how to increase accessibility, educators considered strategies to tap into multiple modalities during sessions, such as including both verbal and written communication, as well as ways to broaden spoken participation. Other discussions focused on possibilities for co-facilitating sessions and ideas for using the Museum and incorporating Museum resources online. The team also brainstormed a variety of options for offerings in terms of length, format, and scheduling with a flexible approach to help meet teachers' needs during the pandemic, and planned to offer both individual sessions as well as a series of multiple sessions for a deeper dive into particular topics for an extended duration. Another important step for the fall was to collect additional teacher demographic data including race/ethnicity and gender on surveys administered after PL offerings to learn more about participants and who we were reaching. 


\section{SITUATING GOTTESMAN CASE STUDY FINDINGS ACROSS TEACHER EDUCATION PROGRAMS}

Participation Remained Strong Throughout the Closure.

Examining participation patterns across teacher programs, we found that participation did not drop dramatically due to the COVID-19 pandemic. For instance, the attendance rate for teachers across 13 Urban Advantage courses offered online during the closure was $78 \%$, similar to the $81 \%$ rate of the previous year. In some cases, we found slight to considerable increases in participation with remote offerings. Similarly, in the Master of Arts in Teaching Earth Science Residency Program, we found slight increases in attendance at Mentor Academy (PL for mentor teachers), new teacher induction sessions (PL for first- and second-year teachers), and with a PL group of fifth year teacher graduates focused on culturally responsive science education. For example, the average number of participants for first year teachers in induction, attendance rose from 12 on average (in person) preCOVID-19 to 14 on average (remote) during COVID-19; for second year teachers, average attendance increased from 7 (in person) pre-COVID-19 to 9 (remote) during COVID-19. Furthermore, there was no evidence of inequitable participation with regard to geography or demographics across teacher programs during the closure. Analysis of data from Urban Advantage did not reveal inequitable patterns in terms of boroughs being over- or under-represented in terms of absences or withdrawals from courses. Similarly, geo-spatial analysis of zip code data of Gottesman PL participants also did not reveal major shifts, showing representation from all NYC boroughs. Taken together, these findings indicate that teachers continued to find value in teacher education programs offered by the Museum and programs were offered in ways that made it possible for teachers to participate remotely.

Appreciation and Support for Online Learning. Across programs, teachers were appreciative of the quick move to online programming. Urban Advantage teachers underscored how much they valued the efforts of the program to make their courses accessible online. They highlighted how quickly and efficiently instructors moved the course online and also offered the usual positive feedback and course content and structure. Preservice teachers in the Earth Science Residency Program also reported a fairly seamless transition of courses online. Similarly, Gottesman teachers reflected surprise and eagerness about the online offerings. The majority of Gottesman teachers shared that their experience in remote learning was the same as in-person learning in terms of level of engagement, quality of discussion, and immediate usefulness of strategies to teaching. In fact, many participants noted benefits to the online format that they felt would have been different in-person such as accessibility, convenience, fewer distractions, and more opportunities to talk with people they might not have otherwise in randomized breakout groups.

Seeing distance learning modeled by AMNH instructors helped participants think about how to improve their own pedagogy online was another cross-program theme that surfaced. Urban Advantage's model of professional learning, in which teachers experience science as learners and then reflect as teachers, allowed teachers to experience remote learning as students of science. Participants, in turn, reported that their experiences in remote Urban Advantage PLs helped them think about how they could improve their own pedagogy online. The Master of Arts in Teaching Earth Science Residency Program received similar reports from preservice teachers, who highlighted the usefulness in seeing faculty model online teaching strategies that they could then implement in their future classrooms as they would inevitably start their first year of teaching remotely due to the pandemic. Findings from Gottesman feedback were also similar, where teachers were extremely enthusiastic about learning strategies they could use online themselves.

Perhaps in light of the rapid move to online teaching, and the need for considerable support, there was strong interest in having AMNH provide more support for online instruction and pedagogy. Master of Arts in Teaching Earth Science Residency Program survey data indicated that residents, graduates, and mentor teachers were interested in learning about more online strategies, technology platforms and programs. Participants were also interested in having opportunities in the program to learn from others about online teaching strategies and resources. In Gottesman, there was unanimous enthusiasm for online offerings: $100 \%$ of survey respondents from August sessions expressed interest in remote PL throughout the school year.

A need for flexibility and adaptation for successful learning was another theme across teacher programs. Related to concerns about workload, online teacher learners reported many external pressures that affected their coursework, particularly during Spring 2020. In online programs and courses like Seminars on Science and Coursera, for instance, many learners had sick relatives, or lost loved ones, or were sick themselves. Many were juggling the immediate transition to online teaching themselves while also caring for children at home. There was an increase in the number of learners who needed more flexibility in terms of course deadlines. While this did not surface as strongly in feedback from Gottesman teachers, this was an approach that the team adopted as well as seen with alternate formats and scheduling of PLs and offering repeated sessions.

Across programs, teachers shared challenges related to amount of screen time, ability to stay focused, and lack of social interaction. Master of Arts in Teaching residents shared challenges related to being online for considerable periods 
of time with several reporting concerns about staying focused, motivated, and effects related to hours of screen time. For future online courses, residents suggested providing options to lessen the screen time, such as shortening the length of classes and increasing the frequency or providing more breaks, and providing slides in advance. Similarly, Gottesman teachers also expressed challenges related to working online while at home, wanting more breaks during sessions, and missing personal connections.

Making Scientific Phenomena Visible: Challenges and Affordances of Online PL. One of the challenges raised in the move to online teaching was how to make scientific phenomena visible to teachers online. Educators in Urban Advantage, for instance, selected a variety of strategies: from shipping materials to teachers to do hands-on work in their kitchens, to spending hours preparing videos of phenomena, to planning self-guided walks in teachers' own communities. Gottesman educators developed a set of courses focused on the scientific phenomenon of how the Blue Whale, the largest animal to ever live, can survive by eating something so small. Teachers used essays, videos, and a graphing tool to analyze and interpret data to look for patterns to help understand the phenomenon. In this case, using secondary data sets seemed especially 'translatable' to online learning.

In some cases, educators found online instruction could provide a closer look at phenomena than in person. In Urban Advantage, instructors took advantage of the online platform to create videos to show participants science reactions quickly using time lapse functions and come to conclusions more rapidly than in real-time. For example, for a course in which teachers would typically learn at the New York Botanical Garden, an Urban Advantage instructor created a timelapse video of a Sundew flower with various food sources. Typically, teachers would take observations throughout the day; however, in the online format, teachers were able to view the experiment in time lapse, making the finding that the plant is carnivorous perhaps even more surprising than it would have been. To reimagine scientific fieldwork excursions in the Master of Arts in Teaching Earth Science Residency Program, scientists and curators in the Science Research Practicum used a variety of technologies when creating virtual field trips for residents, combining high-resolution photos and mosaics of outcrops, as well as video, animation, and Google Earth to gain a sense of locality and context. Through virtual field trips, program faculty were able to model observations and lead discussions at outcrops with residents so that they could then make their own observations and take fieldnotes.

\section{Family Engagement.}

Engaging with Families Directly during Remote Learning. With school shifting to remote learning in the spring, par- ents became more directly involved in their children's daily learning and were eager for resources and materials. Urban Advantage and other programs for teachers recognized they may have an expanded role to play in helping families directly with facilitating their children's learning in science. Gottesman also offered a session for teachers on emphasizing family engagement for student success, featuring tools and strategies to build relationships and help bring families into their child's learning. For example, teacher programs have an opportunity to help families and parents develop a deeper understanding of what it looks like to learn scienceand what that could look like in partnerships between parents and children.

\section{Addressing Equity and Responsiveness in Online Teacher Programming.}

Centering Diversity, Equity, Inclusion and Culturally Responsive and Sustaining Education in Remote and Blended Teaching and Learning. While critical before the pandemic, with the increased awareness and understanding of social and racial inequities and movements for social justice, online learning opportunities for teachers during the pandemic focused on teaching in equitable, inclusive, and culturally responsive ways. The Master of Arts in Teaching Earth Science Residency Program developed new programming for residents at the start of the program featuring workshops on racial literacy and diversity, equity, inclusion, and access when the summer museum teaching residency was cancelled. This also provided opportunities for faculty to build connections with culturally responsivesustaining education in courses. Professional learning for graduates also featured healing-centered, trauma informed pedagogy facilitated by other program graduates. This was also apparent in Gottesman, with new online offerings on culturally responsive teaching using nature journaling as a tool and plans for upcoming sessions on museum resources and strategies for teaching virtually about Haudenosaunee culture while addressing issues of cultural representation and on perspective taking while observing dioramas.

\section{BEYOND THE CLOSURE: CONTINUED REMOTE TEACHER PROFESSIONAL LEARNING}

During the historic closure of the museum during the COVID-19 pandemic, teacher education programs experienced both successes and challenges, as evidenced by a careful analysis of data from Gottesman teacher offerings. The evaluation of teacher programming has provided opportunities to identify and build on the strengths, innovations, and creativity that have surfaced and consider how to strategically take lessons learned from this time forward. AMNH reopened to the public on September 9th, 2020 at 
reduced capacity with timed entry and advanced ticketing and opened at full capacity on May 19th, 2021. Several areas of the museum such as halls featuring touch tables and interactives remained closed. While some programs explored hybrid or blended models, the vast majority of teacher education, including Gottesman PL, remained virtual throughout 2020-2021. Adopting a responsive approach to teachers' needs during this time, Gottesman has continued with flexible and accessible formats, an affordance of online professional learning (NASEM, 2016). What remained consistent in our programs was features that matter for teacher professional learning-content, strategies, support, and in science, teachers engaging in inquiry themselves.

Offerings have expanded to provide more support for online science teaching and learning, opportunities for individual workshops and series of sessions that build on one another to deepen learning, as well as new timely topics informed by healing-centered, trauma-informed pedagogy and culturally responsive and sustaining education. There has also been focus on broadening opportunities for teachers to interact with scientists and curators in PL, a hallmark of AMNH education programs over decades. The beginning of the pandemic and heightened focus on equity helped to inform us about the need for more comprehensive and consistent demographic data. With an emphasis on learning more about teacher participants, audience reach, and enhancing responsiveness, Gottesman began consistently collecting additional demographic data from participants including race and ethnicity, gender, and zip code. Thus, one important takeaway from this time, and applicable to any education program, has been the importance of learning about your participants, gathering data consistently and systematically, and examining who you are (and are not) reaching.

The effort to collect more demographic data from participants has meant that we have a deeper understanding of who attended teacher PL during the year following the initial closure of the museum. For example, in the fall of 2020, 270 teachers participated across Gottesman's 11 teacher PL sessions. We learned that teacher characteristics were fairly similar to earlier data from Chancellor's Day and August sessions with high percentages of veteran teachers $(57 \%)$ from middle (28\%) and high schools $(28 \%)$ represented and is consistent with data from previous years. With fall 2020 survey data ( $\mathrm{n}=211 ; 78 \%$ response rate) featuring additional demographic details, we learned that approximately 53\% of participating teachers identified as White with fairly even distributions amongst teachers identifying as Asian (16\%), Hispanic or Latino (14\%), and Black or African American (11\%); and $82 \%$ identified as female. This demographic breakdown resembles the racial and ethnic diversity of teachers in NYC with $42 \%$ teachers of color, according to 20162017 data (NYSED, 2019). Throughout the year, Gottesman continued to provide online, content focused teacher PL, which was especially critical as the NYC DOE had not yet started to offer support to teachers at that time. Thus, there is opportunity to further center equity in our work.

\section{IMPLICATIONS}

Across teacher education programs, we continue to learn from experiences during this time and how it can inform future planning. In light of the literature on education in emergencies and learning from other cultural institutions, three themes emerged that have potential to shape our work going forward: leveraging remote learning to increase access and equity; gaining clarity about our shared vision of good online science teaching; and being explicit about how we are modeling this pedagogy online. We believe these themes are potentially transferable and can inform the work of other teacher education programs in the field.

\section{Continue to Offer Remote Teacher Professional Learning}

Sessions. First, because we did not find evidence of inequitable participation, and in fact, found some evidence that during this time the online platform may have provided greater access to teachers, this suggests that continuing some form of online professional learning for teachers in our work going forward could be quite important. Further, it may enable us to reach audiences beyond New York City and state. Given the success of the transition of teacher education programs online and the affordances they provide in terms of flexibility and accessibility, continuing some versions of remote offerings in addition to in person experiences could potentially increase reach with teachers. There is potential for an array of programming modalities in the future, which can also provide opportunities to increase reach to audiences and potentially to continue addressing and centering issues of equity, particularly considering those who might not be able to visit the museum in person. Providing a portfolio of delivery options can allow opportunities to continue longterm relationships with educators and also expand reach and access. Furthermore, as we continue to collect more nuanced demographic data, we can continue to better understand how to increase the diversity of our participants as well as ensure we are understanding and surfacing the needs of the teachers with whom we work in more complex and responsive ways.

In response to this implication of our work, Gottesman plans to continue to offer remote PL in 2021-2022. New content focused offerings in summer 2021 include using Museum resources to learn about animal adaptations, astronomy by sight, and sessions responsive to the current environment such as supporting learners in returning to the classroom in person and deepening family engagement and building community. Research-based design features for teacher PL, which we've seen as effective for teacher learning both in person and online, will remain-active participation in 
which teachers are immersed in inquiry, collaboration in small groups using breakout rooms, science content focus on particular phenomena, close connection with teachers' classroom practice with time for reflection, providing models of effective online instruction, and using educative curriculum for teachers and students.

\section{Develop a Shared Vision for Good Online Science} Teaching. Second, we see an important role for professional learning to model strategies in relationship to a vision of good teaching and learning online. One of the challenges of the rapid move to remote learning this year was the urgency of the moment and the shifts to online teaching, which made it difficult to develop a clear vision of good teaching in a remote environment. Rather, many teachers and schools scrambled to create online learning opportunities for students, with little time or support to draw upon research and learning about effective online teaching. We see potential for our work to help make transparent and explicit a vision of good and equitable online teaching and learning and to help teachers deepen their understanding of the practices that reflect that vision. At AMNH, with our strong history of teaching online (Steiner et al., 2016; Steiner et al., 2006), based on research on remote learning, there is an opportunity to help communicate what that vision can look like to teachers and model these practices.

To address the finding that we needed to strengthen our vision of good online science teaching, we conducted monthly meetings during 2020-2021 with the Research and Evaluation Group at AMNH to look, collectively, at the data from the evaluation of programs during the closure. The Research and Evaluation group consists of researchers and educators that span programs in the Education department, including Children and Family Learning, Youth Programs, the Gottesman Center for Science Teaching and Learning, the Master of Arts in Teaching Earth Science Residency Program, Urban Advantage, Seminars on Science, and Public Programs, and our collective goal is to advance research and evaluation efforts across the museum (MacPherson et al., 2019). Following a session in which participants analyzed evaluation data from the pandemic relating to their specific program, the group decided that a key finding was that we needed more clarity on what constituted "high quality" online teaching and learning experiences, was there consensus about "best practices" for teaching and learning online, and what were the specific components of good online teaching at $A M N H$ ?

Research on online education generally doesn't find a significant difference in achievement between online and in-person formats, though direct comparisons are exceedingly difficult (Loeb, 2020; Nguyen, 2015). Research comparing online to face-to-face teacher PL programs finds a similar lack of significant difference in teacher learning and

student outcomes, though findings are highly context dependent (e.g. Fishman et al, 2013). Furthermore, there is no comprehensive theory guiding online course design (Simonson et al., 2019). Therefore, finding a list of "ingredients" for an effective online professional learning course isn't necessarily straightforward.

To author a comprehensive theory guiding our own course design, the Research and Evaluation Group used a structured discussion protocol to examine the data from the pandemic evaluation, especially feedback from teachers about what worked and what didn't work, and combined these findings with our own reflections about strategies and tools that seemed to be effective in our sessions. Specifically, groups answered, "What teaching strategies did you find most helpful or important when teaching online? What teaching strategies were most successful in your work during the move to online? What teaching strategies were harder to do when teaching online? What strategies did you find successful to help audiences connect and talk to one another and learn?"

In a final meeting, groups nominated several "principles critical to our vision of good science teaching online" on jamboards. The ideas were tallied and the top nominations

Table 5. A set of principles that constitute AMNH's vision of good online science teaching.

\section{Principle}

Instructor provides opportunities for learners to interact with each other

Formative and summative provided throughout the learning experience and feedback from the instructor is provided.

Planning around scientific phenomena

ntegrating the interests of the audience, connecting to learners, eliciting and working with students' ideas

Creating built-in support for learners and instructors, especially around new technology authentic scientific research assessment opportunities are

\section{Looks like/Sounds like at AMNH}

Use of breakout rooms with structured prompts, generating and organizing ideas on a Jamboard or Google Slide

Instructor asks participants to "put an answer in the chat,'

Use of Zoom polls, Peardeck, Kahoot and other interactive tools to collect formative assessment data

Professional learning focused around a big idea in science, for example:

The Blue Whale is the largest animal to ever live, but survives on a tiny food source

The Sundew is a plant, and it eats animals

Opening with an icebreaker where participants share their mood

Integrating opportunities for participants to share their ideas on a Jamboard or in the chat

Expanding offerings to cover a range of topics to appeal to diverse interests and needs

Providing access to scientists and Leveraging museum resources such as objects from the collection that can be viewed online

Use of authentic secondary data sets (NOAA, River Ecology Case Study, Blue Whale feeding data) Scientists involved in planning and facilitating online course offerings

The development of "tech support" for all Gottesman online sessions 
are shown in Table 5.

We aim to use this list as a set of principles for the design of our online course offerings going forward. As we realized by generating this list of principles, most of what we know about education can be applied to online education. The principles identified above, besides "creating support around new technology," are all essential to in-person learning as well. However, as we go forward with creating remote courses, we now have a list of "gotta have it" ideas and examples from our own practice this past year, which will guide course design.

At the same time, even as principles emerge, we also noticed that some key ideas are still in the process of developing and important to include in our 'list' of key practices. As we continually examine and probe issues of equity and racism individually and collaboratively, equity and justice-oriented practices are of central importance and have to inform how we push this work forward. We recognize that we will also need to expand and push our understanding of a vision of good online science teaching to explicitly call out the role of anti-racism and socially just, equitable, and ambitious science teaching, and actively strive to confront and dismantle oppression and biases. Concerns about socially just science education, and an increased need for anti-racist education are resonating throughout science education, and will be essential for us to include in our focus and our vision.

Model Pedagogy that Supports Our Vision. Finally, because we heard from teachers about the value of seeing good teaching modeled, and research findings supporting the power of professional learning that is "close to practice" (Penuel et al., 2007), we see potential in using the remote setting to continue to help reveal and share online pedagogical strategies that support our vision of good science teaching. Importantly for teacher professional learning, this must also involve modeling culturally responsive and sustaining science teaching practices and anti-racist pedagogical practices. Schooling on remote platforms may need to continue in one form or another in the future, so the more we can support teachers in learning and practicing research-based pedagogical strategies that are especially powerful in an online environment, the better. As the literature on education in emergencies suggests, we need to be prepared for future needs related to online learning.

To build education back better, there is opportunity to further center equity and anti-racism, helping to shift the focus on education beyond coverage to a meaningful vision of deeper learning. By continuing to explicitly problematize key ideas in teaching and learning, by being prepared and ready to dive into socio-scientific challenges using research on culturally sustaining practices, by bringing deep knowledge of the research on teaching and learning and a clear, strong vision of teaching science online and in person, we can continue to play a critical role in education even at this most perilous moment.

\section{AUTHOR INFORMATION \\ Corresponding Author}

Jamie Wallace. Education Department, American Museum of Natural History. Central Park West at 79th Street, New York, NY, 10024. (212) 769-5241. jwallace@amnh.org

\section{Author Contributions}

The manuscript was written through contributions of all authors. All authors have given approval to the final version of the manuscript.

\section{ACKNOWLEDGMENTS}

We would like to recognize and thank the members of the AMNH education department for their invaluable contributions to this effort, and especially our colleagues in the Gottesman Center for Science Teaching and Learning, Linda Curtis-Bey, Alison Sheehan, Melanie Cohen, Rebecca Taylor, the talented team of teacher educators, and the Research and Evaluation Group. We also express great appreciation to Hannah Hatch for her wonderful work on geo-spatial analysis and GIS mapping.

\section{ABBREVIATIONS}

AMNH: American Museum of Natural History; NGSS: Next Generation Science Standards; PL: Professional Learning; SEL: Social-Emotional Learning

\section{REFERENCES}

American Alliance of Museums (AAM) and Dynamic Benchmarking. (2020). National survey of COVID-19 impact on United States museums. https://www.aam-us.org/ wp-content/uploads/2020/07/2020_National-Survey-ofCOVID19-Impact-on-US-Museums.pdf

Darling-Hammond, L., Hyler, M.E., and Gardner, M. (2017). Effective teacher professional development. Palo Alto, CA: Learning Policy Institute.

Desimone, L.M. (2009). Improving impact studies of teachers' professional development: Toward better conceptualizations and measures. Educational Researcher 38(3), 181199.

Fishman, B., Konstantopoulos, S., Kubitskey, B. W., Vath, R., Park, G., Johnson, H., and Edelson, D. C. (2013). Comparing the impact of online and face-to-face professional development in the context of curriculum implementation. Journal of Teacher Education, 64(5), 426-438. 
Hallgarten, J. (2020) Evidence on efforts to mitigate the negative educational impact of past disease outbreaks. K4D Helpdesk Report 793. Education Development Trust. https://opendocs.ids.ac.uk/opendocs/bitstream/handle/20.500.12413/15202/793_mitigating_education_effects_of_disease_outbreaks.pdf? sequence $=6 \&$ isAllowe $\overline{\mathrm{d}}=\mathrm{y}$

Haug, B. S., and Mork, S. M. (2021). Taking 21st century skills from vision to classroom: What teachers highlight as supportive professional development in the light of new demands from educational reforms. Teaching and Teacher Education, 100, 103286.

Jacobs, J. (2020, May 6). Natural history museum slashing staff with layoffs and furloughs. The New York Times. https:// www.nytimes.com/2020/05/06/arts/design/natural-history-layoffs-virus.html

Loeb, S. (2020, March 20). How effective is online learning? What the research does and doesn't tell us. EdWeek. https:// www.edweek.org/technology/opinion-how-effective-isonline-learning-what-the-research-does-and-doesnt-tellus/2020/03

MacPherson, A., Hammerness, K., and Gupta, P. (2019). Developing a set of guidelines for rigorous evaluations at a natural history museum. Journal of Museum Education, 44(3), 277-285.

The National Academies of Sciences, Engineering, and Medicine (NASEM). (2016). Science teachers' learning: Enhancing opportunities, creating supportive contexts. Wilson, S., Schweingruber, H., and Nielsen, N., Eds. Washington, DC: The National Academies Press. https://doi. org/10.17226/21836

New York State Department of Education (NYSED). (2019, December). Educator diversity report. http://www.nysed.gov/ common/nysed/files/programs/educator-quality/educator-diversity-report-december-2019.pdf

Nguyen, T. (2015). The effectiveness of online learning: Beyond no significant difference and future horizons. Journal of Online Learning and Teaching 11(2), 309-319.

Penuel, W. R., Fishman, B. J., Yamaguchi, R., and Gallagher, L. P. (2007). What makes professional development effective? Strategies that foster curriculum implementation. American Educational Research Journal, 44(4), 921-958.

Pogrebin, R., and Cooper, M. (2020, March 12). New York's major cultural institutions close in response to Coronavirus. The New York Times. https:/www.nytimes.com/2020/03/12/ arts/design/met-museum-opera-carnegie-hall-close-coronavirus.html

Shapiro, E. (2020, March 15). New York City public schools to close to slow spread of Coronavirus. The New York Times. https://www.nytimes.com/2020/03/15/nyregion/nycschools-closed.html

Simonson, M., Zvacek, S., and Smaldino, S. (2019). Teaching and learning at a distance: Foundations of distance education (7th ed.). Charlotte, NC: Information Age Publishing, Inc.
Steiner, R.V., Applewhite, A., Aquino, A.E., Gugenheim, L.J., Janelli, M., Kinzler, R., Macdonald, M., Randle, D., Taber, K., Wallace, J., Wolff, D., and Stokes, L. (2016). Online teacher professional development from the American $\mathrm{Mu}$ seum of Natural History. In C. Dede, A. Eisenkraft, K. Frumin, and A. Hartley (Eds.), Teacher learning in the digital age: Online professional development in STEM education (pp. 87-106). Cambridge, MA: Harvard Education Press.

Steiner, R.V., Macdonald, M., Kinzler, R., and Gordon, M. (2006). Seminars on Science: Online science professional development at the American Museum of Natural History. In C. Dede (Ed.), Online professional development for teachers: Emerging models and methods (pp.137-154). Cambridge, MA: Harvard Education Press.

Sweeney, L., and Frederick, J.K. (2020). Ithaka S+R art museum director survey 2020. Ithaka S+R. https://srithaka.org/ wp-content/uploads/2020/11/SR-Report-Art-Museum-Director-Survey-2020-111220.pdf

UNESCO. (2020). Museums around the world in the face of COVID-19. https://unesdoc.unesco.org/ark:/48223/ pf0000373530? 1 locale $=$ en

Wilson, S. M. (2013). Professional development for science teachers. Science, 340(6130), 310-313. 